\title{
Review on automated follicle identification for polycystic ovarian syndrome
}

\author{
A. A. Nazarudin', Noraishikin Zulkarnain², A. Hussain ${ }^{3}$, S. S. Mokri' ${ }^{4}$, I. N. A. M. Nordin 5 \\ ${ }_{1,2,3,4}$ Centre for Integrated Sy stems Engineering and Advanced Technologies (INTEGRA), Faculty of Built \\ and Environment, Universiti Kebangsaan Malay sia, Malaysia \\ 1,2,3,4 Department of Electrical, Electronic and Sy stems Engineering, Faculty of Built and Environment, Universiti \\ Kebangsaan Malaysia, Malaysia \\ ${ }^{5}$ Cybernetics Research Group, Faculty of Engineering Technology, Universiti Tun Hussein Onn Malaysia, Malay sia
}

\begin{tabular}{|c|c|}
\hline Article Info & ABSTRACT \\
\hline & \multirow{10}{*}{$\begin{array}{l}\text { Poly cystic Ovarian Syndrome (PCOS), is a condition of the ovary consisting } \\
\text { numerous follicles. Accurate size and number of follicles detected are crucial } \\
\text { for treatment. Hence the diagnosis of this condition is by measuring } \\
\text { and calculating the size and number of follicles existed in the ovary. } \\
\text { To diagnosis, ultrasound imaging has become an effective tool as it is non } \\
\text { invasive, inexpensive and portable. However, the presence of speckle noise } \\
\text { in ultrasound imaging has caused an obstruction for manual diagnosis which } \\
\text { are high time consumption and often produce errors. Thus, image } \\
\text { segmentation for ultrasound imaging is critical to identify follicles for PCOS } \\
\text { diagnosis and proper health treatment. This paper presents different methods } \\
\text { proposed and applied in automated follicle identification for PCOS diagnosis } \\
\text { by previous researchers. In this paper, the methods and performance } \\
\text { evaluation are identified and compared. Finally, this paper also provided } \\
\text { suggestions in developing methods for future research. }\end{array}$} \\
\hline Received Sep 18, 2019 & \\
\hline Revised Nov 21, 2019 & \\
\hline Accepted Dec 28, 2019 & \\
\hline Keywords: & \\
\hline Automated segmentation & \\
\hline Follicle identification & \\
\hline Image segmentation & \\
\hline PCOS & \\
\hline & \\
\hline
\end{tabular}

This is an open access article under the CC BY-SA license.

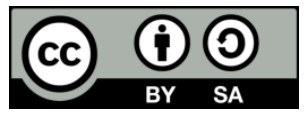

\section{Corresponding Author:}

Noraishikin Zulkarnain,

Department of Electrical, Electronic and Systems Engineering,

Centre for Integrated Systems Engineering and Advanced Technologies (INTEGRA),

Faculty of Built and Environment, Universiti Kebangsaan Malaysia,

43200 UKM, Bangi, Selangor, Malaysia.

Email: shikinzulkarnain@ukm.edu.my

\section{INTRODUCTION}

Polycystic Ovarian Syndrome, -or commonly known as PCOS is described as a condition of numerous primordial follicles in the ovary. This disorder is diagnosed by ultrasound imaging which gives important information on the ovarian follicle quantity and size. Ovarian follicles are spherical, fluid-filled structures in which oocytes (eggs) develop. In two dimensional ultrasound imaging, ovarian follicles appeared as dark, roughly circular regions. In PCOS, the condition is characterized as having 12 or more follicles in the ovary with the size of $2-9 \mathrm{~mm}$ and/or the volume of $10 \mathrm{~cm}^{3}$ [1]. The number and size of follicles in the ovary is vital in a healthy women's reproductive system, especially those who are trying to conceive. Ultrasound imaging are non-invasive, portable and inexpensive. Therefore ovarian ultrasound imaging has become an effective tool in PCOS diagnosis and ovarian follicle identification. However, ultrasound imaging has poor quality of images which disturbed by speckle noise [2]. This disturbance are causing difficulties to recognize the ovarian follicles especially by medical practitioners with manual diagnosis. Manual diagnosis and identification is laborious, time consuming and often produce errors [3]. 
Thus, many researchers have been working on developing an automated algorithm to identify ovarian follicles for PCOS diagnosis.

In developing an automated follicle identification for PCOS diagnosis system, the follicles are the regions of interest (ROIs) in an ovarian ultrasound image, which need to be detected using image processing techniques. The basic image processing steps consist of pre-processing, segmentation, feature extraction and classification [4]. One of the crucial steps is segmentation, where this is to help identifying region of interest, namely the follicles. Hence the automated follicle identification for PCOS diagnosis systemis to identify the number and size of ovarian follicles using image segmentation.

Among the earliest study of automated follicle identification using image processing are led by Krivanek et al. [5] in 1998 and Potocnik et al. [6] in 2002. In their research, Potocnik [6] highlighted the difficulties of recognising smaller follicles and distingushing adjacent follicles which has no expressive boundaries to each other. Later on, in 2017, Faghih et al. [7] raised the same issues while reviewing the literature for their studies. Based on previous studies, the smaller follicles or follicles that are adjacent to each other were neglected or unnoticed and some methods have the tendency of over-segmenting which will effect the treatment given.

Based on previous comparative studies in automated follicle identification for PCOS diagnosis $[2-3,8]$, researchers concluded it is needed to develop algorithm in removing the speckle noise in the ultrasound image effectively and to investigate features extraction for classification of the ovary. Thus, this paper objective is to review previous methods of image segmentation in ultrasound image for automated follicle identification for PCOS diagnosis; the methods applied and the parameter for evaluation. To study the image segmentation methods applied by previous researchers, this paper applied snowball method. This method had focused on the literature regarding automated follicles identification in ovarian ultrasound images. Therefore, the review on different methods and performance evaluation will be presented. The rest of the paper is organized as follows: in section 2 describes the methods suggested by previous researchers. Later in section 3 is shown the table review for the methods of automated follicle identification with performance evaluation. In section 4 is the conclusion and future work suggestions.

\section{IMAGE SEGMENTATION METHODS}

Medical practitioners have been using ovarian ultrasound images to diagnose PCOS condition. This is due to ultrasound is non-invasive and less time consuming. In ultrasound, the image of follicles in the ovaries will appear as roughly dark circles. The images of normal and polycystic ovary as shown in the Figures 1 and 2.

From these images, medical practitioners will manually calculate the size and number of follicles existed. However, this approach is time consuming and often produce errors. Therefore, researchers have been developing and exploring an automated image segmentation for follicle identification to diagnose PCOS condition. Various research groups have devised different automated image seg mentation techniques for follicle identification. Among the foremost groups are led by Krivanek et al. [5] in 1998 and Potocnik et al. in 2002 [6]. In image segmentation for automated follicle identification, researchers applied various methods with improvisations namely watershed transform, thresholding, region based growing, edge based, clustering, artificial neural network and mathematical morphology. This section presents an overview of researches on automated follicle identification techniques.

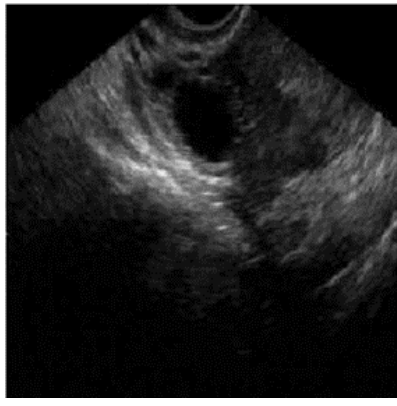

Figure 1. Normal ovary [8]

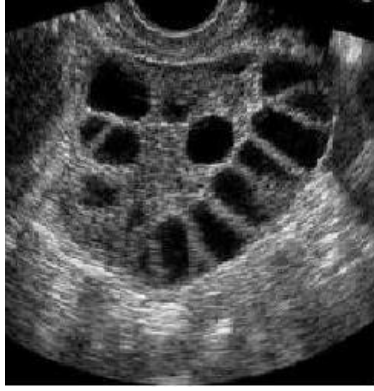

Figure 2. Polycystic ovary [8]

\subsection{Watershed transform}

Krivanek and Sonka [5] introduced a multistep automated segmentation employing watershed segmentation and graph search method to determine the inner border of the follicles. In the application of this 
method, minimal manual segmentation by medical practitioner was involved. The evaluation of this technique was by comparing the maximum and root mean square (RMS) borders positioning between computer-determined and observer-defined. It was shown that the RMS for computer-determined is more accurate. In 2011, Deng et al. [9] proposed an enhanced watershed algorithm, namely labeled watershed algortihm for local minima extraction because the classic watershed algorithm often leads to excessive segmentation and needs minimal medical practitioner interaction. The labeled watershed algoritm was applied after adaptive morphological filtering of image.

In the research for a novel real-time follicle identification, [7] Faghih et al. applied watershed algorithm for the condition if there is a possibility of multiple follicles existed in the region of interest of a very dark image with high percentage of dark pixels. This algorithm was introduced to minimize the faulty in ignoring the follicles which are adjacent to each other or too small for segmentation. Some researchers applied watershed segmentation method as image enhancement, in the pre-processing stage of image processing, for ultrasound image [10-11].

\subsection{Region growing method}

Potocnik et al. in 2002 [6], proposed region growing method by making the homogenous region of interest grow until they clash with the object's boundary. The recognition rate of this method was around $78 \%$. However, they concluded this method had the difficulties in detecting smaller follicles due to their brightness and poorly perceivable. This method was modified with two additional criteria to merge with region of interest [12]. Lawrence [12] highlighted, although the modified method is known as a better follicle recognition rate, it is lacking in robustness. They suggested for deploying a more robust aut omated follicle identification in the future.

In 2011, Deng et al. [9] constructed a cost map for the region growing method and assigned a cost function to the cost map for follicle identification. This method is more effective than the two mentioned above and achieved higher rate of follicle identification. By utilizing spatial connectivity of follicles and the contour of ovary, Sitheswaran et al. [10] constructed cost map depending one the pixel's relative location for region growing algorithm. The recognition rate was the same as Deng et al. In 2015, Adiwijaya applied region growing method where aims to compare both the identified seed and homogeneous region to enlarge its region for reaching the real follicle limits [13]. However this method limited to ultrasound image with homogeneity, where as most ovarian ultrasound images are inhomogeneous.

\subsection{Edge based method}

Edge based method for image segmentation falls into two categories: gradient based method and soft computing approach [2]. In this section, the category of edge based method widely found on literature is the gradient based method. Researchers applied the gradient based method with Canny operator [14-17]. There are few others operators for edge based method in segmentation such as Sobel, Prewitt but based on the review, it is found that most researcher applied Canny operator for edge based method as Canny operator gave the most satisfying result [14]. Hiremath et al. [14] compared edge based method segmentation with manual segmentation done by medical practitioner. It was shown that the increase of false acceptance rate and false rejection rate of the proposed method is lower than the manual segmentation. Thus the proposed method was more efficient. Considering follicles are in circular shape with areas about $4-80 \mathrm{~mm}^{2}$ for PCOS ovarian follicle and about $314 \mathrm{~mm}^{2}$ for normal ovarian follicle, threshold values for area of each region of interest is calculated and number of important follicles identified is found out [15].

\subsection{Active contour method}

Among the commonly applied method for image segmentation for ovarian ultrasound image is active contour without edge based. In segmentation stage, Hiremath and Tegnoor [18] applied this method for ovarian ultrasound image segmentation to detect the follicles existed. The average of the proposed method was $96.66 \%$ with $3.33 \%$ false rejection rate. Later they applied this method while introducing fuzzy logic inference for ovary classification [19].

In 2015, Kumar and Srinivasan [20] improved this method by improvising the Chan-Vase method and combining with Split Bregman optimization to help with identifying small follicles of less than $2 \mathrm{~mm}$ diameter. The average computational time for the proposed method is 24.15 seconds. In 2017, Lestari [21] applied morphological operation to the Chan-Vase model to remove imperfections that appeared during segmentation and achieved a better result. Meanwhile, Faghih [8] applied active contour method for the condition where the percentage of the very dark pixels in a compressed image is very low to create a new binary mask before morphological processing. 


\subsection{Thresholding method}

In this method, it attempts to determine an intensity value, called the threshold, of the image by creating binary partitioning of the image intensities. The segmentation is achieved by grouping the pixels with greater intensities of the threshold into one class[22]. The pixels darker than their surrounding were scanned row wise (horizontal scanning) and column wise (vertical scanning) [23]. Then the resulted image is fused to get the dark follicle in the white background. Mehrotra [23] applied this method and in their research the difference in the error rate is less compared to manual segmentation. Meanwhile Rihana [24] achieved a promising result of $90 \%$ accurancy for this method.

\subsection{Clustering method}

Clustering method to group the pixels based on similarity. In image segmentation of ovarian ultrasound for PCOS, two different clustering algorithms were applied by researchers. Fuzzy c-means clustering was applied for the segmentation of follicles from the ovarian ultrasound images. This method's performance was calculated using means square error (MSE). The lesser the MSE, the better the efficiency of the method [25]. Park [26] proposed fuzzy c-means clustering as an alternative for image segmentation of brachial ultrasound image. Another clustering algorithm is K-Means clustering algorithm [27]. For this algorithm, authors evaluated structural similarity, false acceptance rate and false rejection rate to show its efficiency. In 2016, Lee applied K-Means clustering algorithm to detect cervical vertebrae with ultrasound image and achieved a success percentage of $96 \%$ accurancy [28].

\section{REVIEW TABLE}

In this section, the table for image segmentation techniques applied for follicle identification in PCOS diagnosis by previous researchers and the performance evaluation for each research based on section 2 is presented. Table 1 shows the list of papers which studied the automated follicle identification for PCOS diagnosis. In the table, the techniques applied and performance evaluation were explained briefly. Each of the method applied required different parameters of evaluation. From the table, it shows that recognition rate and acceptance rate are among the significantly used parameter for accurancy evaluation of automated follicle identification. The higher the recognition rate and acceptance rate indicates the higher the accurancy of the algorithm applied. By far, the highest recognition rate in automated follicle identification is done by Padmapriya [13] in 2016 with recognition rate of 87.5\% using morphological operation with edge based method using Canny operator. However, in their study, the size of the ovarian follicles was not involved. Based on PCOS definition, the number and size of ovarian follicles existed are one of the determining factors of the syndrome. Hence, the method proposed by Padmapriya is only applicable for cystic ovarian case and further study needed to be done for this method on PCOS condition.

Table 1. Technique and performance evaluation of image segmentation in ultrasound images

\begin{tabular}{|c|c|c|c|c|}
\hline Ref. & Author, Year & Paper Title & Technique & Performance Evaluation \\
\hline [6] & $\begin{array}{l}\text { Krivanek, Sonka, } \\
1998\end{array}$ & $\begin{array}{l}\text { Ovarian ultrasound image } \\
\text { analysis: follicle segmentation }\end{array}$ & $\begin{array}{l}\text { Watershed } \\
\text { transform }\end{array}$ & $\begin{array}{l}\text { Root-mean-square border positioning error } \\
\text { and maximum value decrease indicates the } \\
\text { proposed method is more accurate. }\end{array}$ \\
\hline [7] & $\begin{array}{l}\text { Potocnik, Zazula, } \\
2002\end{array}$ & $\begin{array}{l}\text { Aut omated analysis of a } \\
\text { sequencing of ovarian } \\
\text { ultrasound images. Part I: } \\
\text { segment ation of single 2D } \\
\text { images }\end{array}$ & $\begin{array}{l}\text { Region growing } \\
\text { method }\end{array}$ & $\begin{array}{l}\text { Recognition rate (RR) of follicles is } 78 \% \\
\text { and misidentification rate (MR) is } 29 \% \text {. }\end{array}$ \\
\hline [12] & Lawrence, 2007 & $\begin{array}{l}\text { Computer assisted detection of } \\
\text { polycystic ovary morphology in } \\
\text { ultrasound images }\end{array}$ & $\begin{array}{l}\text { Modified region } \\
\text { growing method }\end{array}$ & $\begin{array}{l}\text { Recognition rate of follicles (RR) is } 83.1 \% \\
\text { and misidentification rate (MR) is } 31.1 \% \text {. }\end{array}$ \\
\hline [9] & Deng, 2011 & $\begin{array}{l}\text { An aut omated diagnostic system } \\
\text { of polycystic ovary syndrome } \\
\text { based on object background }\end{array}$ & $\begin{array}{l}\text { Cost map, region } \\
\text { growing method, } \\
\text { cost function }\end{array}$ & $\begin{array}{l}\text { Increase value of tuning parameter beta } \\
\text { indicates high recognition rate, } \\
\text { misidentification rate. }\end{array}$ \\
\hline [10] & $\begin{array}{l}\text { Sitheswaran, } \\
\text { Malarkhodi, } 2014\end{array}$ & $\begin{array}{l}\text { An effective aut omated system } \\
\text { in follicle identification for } \\
\text { polycystic ovary syndrome } \\
\text { using ultrasound images }\end{array}$ & $\begin{array}{l}\text { Cost map } \\
\text { depending on } \\
\text { pixel's relative } \\
\text { location, region } \\
\text { growing method }\end{array}$ & $\begin{array}{l}\text { Tuning parameter beta ( } \beta \text { ) value increase } \\
\text { showed increase in recognition rate (RR) } \\
\text { and misidentification rate (MR). F1 score } \\
\text { is desireable when tuning parameter is } 6 \\
\text { with RR } 84.04 \% \text { and MR 5.9\% }\end{array}$ \\
\hline [13] & Adiwijaya, 2015 & $\begin{array}{l}\text { Follicle detection on the USG } \\
\text { images to support determination } \\
\text { of polycystic ovary syndrome }\end{array}$ & $\begin{array}{l}\text { Region growing } \\
\text { (region based and } \\
\text { seed based) }\end{array}$ & $\begin{array}{l}\text { Average success of recognition rate } 80 \% \\
\text { when the empirical value for region based } \\
\text { is } 1 \text { while for seed based the recognition } \\
\text { rate is } 79.86 \% \text { when thresval value is } \\
0.005 \text {. }\end{array}$ \\
\hline
\end{tabular}




\begin{tabular}{|c|c|c|c|c|}
\hline Ref. & Author, Year & Paper Title & Technique & Performance Evaluation \\
\hline [14] & $\begin{array}{l}\text { Hiremath, } \\
\text { Tegnoor, } 2010\end{array}$ & $\begin{array}{l}\text { Automatic detection of follicles } \\
\text { in ultrasound images of ovaries } \\
\text { using edge based method }\end{array}$ & $\begin{array}{l}\text { Edge based } \\
\text { method(Canny } \\
\text { operator) }\end{array}$ & $\begin{array}{l}\text { False acceptance rate (FAR) and false } \\
\text { rejection rate (FRR) show increase in } \\
\text { efficiency the accurancy of the proposed } \\
\text { method. }\end{array}$ \\
\hline$[18]$ & Padmapriya, 2016 & $\begin{array}{l}\text { Detection of follicles in poly } \\
\text { cystic ovariansyndrome in } \\
\text { ultrasound images } \\
\text { usingmorphological operations }\end{array}$ & $\begin{array}{l}\text { Morphological } \\
\text { operation with } \\
\text { edge based } \\
\text { method (Canny } \\
\text { operator) }\end{array}$ & $\begin{array}{l}\text { The average recognitionrate for all the } \\
\text { images processed by the proposed method } \\
\text { is } 87.5 \%\end{array}$ \\
\hline$[16]$ & $\begin{array}{l}\text { Hiremath, } \\
\text { Tegnoor } 2010\end{array}$ & $\begin{array}{l}\text { Follicle detection in ultrasound } \\
\text { images of ovaries using active } \\
\text { cont our method }\end{array}$ & $\begin{array}{l}\text { Active contour } \\
\text { without edge } \\
\text { based }\end{array}$ & $\begin{array}{l}\text { Lesser false rejection rate and false } \\
\text { acceptance rate in proposed method } \\
\text { indicates the accurancy of follicle } \\
\text { identification increased. }\end{array}$ \\
\hline [23] & Mehrotra, 2011 & $\begin{array}{l}\text { Automated ovarian follicle } \\
\text { recognition for polycystic ovary } \\
\text { syndrome }\end{array}$ & $\begin{array}{l}\text { Scanline } \\
\text { thresholding }\end{array}$ & $\begin{array}{l}\text { Difference in the errorrate is lesser } \\
\text { indicates the effectiveness of the proposed } \\
\text { method. }\end{array}$ \\
\hline [24] & Rihana, 2013 & $\begin{array}{l}\text { Automated algortihm for } \\
\text { ovarian cysts detection in } \\
\text { ultrasonogram }\end{array}$ & $\begin{array}{l}\text { Scanline } \\
\text { thresholding }\end{array}$ & $\begin{array}{l}\text { Found accurancy of } 90 \% \text { as a promising } \\
\text { result with } 88.33 \% \text { sensitivity and } 95 \% \\
\text { specificity. }\end{array}$ \\
\hline$[25]$ & Raj, 2013 & $\begin{array}{l}\text { Detection of cysts in ultrasonic } \\
\text { images of ovary }\end{array}$ & $\begin{array}{l}\text { C-Means } \\
\text { Clustering }\end{array}$ & $\begin{array}{l}\text { Lesser mean square error (MSE) in peak } \\
\text { signal to noise radio (PSNR). }\end{array}$ \\
\hline
\end{tabular}

\section{CONCLUSION AND FUTURE WORK}

Polycystic ovarian syndrome most commonly diagnosed by ultrasound by medical practitioners as it is inexpensive and non-invasive. In PCOS diagnosis it is important to know the size and number of ovarian follicles that portray the characteristic of this syndrome for medical practitioner to administrate the correct treatment. Manual follicle identification in ultrasound image have the flaws of time consuming and often produce errors. Due to that reason, automated follicle identification methods have been explored by many researchers and still being develop for better diagnosis in the future. This review paper has surveyed image segmentation techniques and algorithm proposed by many researches. Automated follicle identification eases the laborious work faced by medical practitioners. Various forms of image processing techniques have been applied for automated follicle identification for PCOS diagnosis.

While reviewing the literature, some researchers highlighted the condition of small follicles or adjacent follicles were neglected or unnoticed. This condition can seriously affects the treatment given and health condition of the patient. Other than that, each of the method applied does not apply the same pre-processing filtering algorithm to remove the speckle noise. This has led to different parameter of evaluation. Thus, in the future, further research is needed to develop the method to remove the speckle noise in the ultrasound images effectively and explore available methods for ovarian ultrasound images in identifying follicles, including the smaller follicles and that are adjacent to each other.

\section{ACKNOWLEDGEMENTS}

The authors would like to sincerely thank to Ministry of Higher Education Malaysia for the support and Universiti Kebangsaan Malaysia (UKM) for the facilities and equipment provided for this research. This work is fully supported by Ministry of Higher Education Malaysia under FRGS research Grant (Vote no. FRGS/1/2018/TK04/UKM/02/15) and research university Grant (Vote no. GGPM-2017-087).

\section{REFERENCES}

[1] S. Jonard et al., "Ultrasound examination of polycystic ovaries: is it worth counting the follicles?," Human Reproduction, vol. 18, no. 3, pp. 598-603, 2003.

[2] R. Saranya and S. U. Maheswari, "A Literature Review on Computer Assisted Detection of Follicles in Ultrasound Images of Ovary," International Journal of Computer Applications, vol. 48, no. 12, pp. 39-40, June 2012. 
[3] I. O. Rabiu, A. D. Usman, A. M. S. Tekanyi, "A Review on Computer Assisted Follicle Detection Techniques and Polycystic Ovarian Syndrome (PCOS) Diagnostic System," International Journal of Computer Trends and Technology (IJCTT), vol. 28, no. 1, October 2015.

[4] P. S. Hiremath and J. R. Tegnoor, "Follicle detection and ovarian classification in digital ultrasound images of ovaries," Advancement and Breakthroughs in Ultrasound Imaging, chapter 7, pp. 168-199,June 2013

[5] A. Krivanek and M. Sonka, "Ovarian ultrasound image analysis: follicle segmentation," in IEEE Transactions on Medical Imaging, vol. 17, no. 6, pp.935-944, Dec. 1998.

[6] B. Potocnik and D. Zazula, "Automated analysis of a sequence of ovarian ultrasound images part I: segmentation of single 2D image," Image and Vision Computing, vol. 20, no. 3, pp. 217-225, March 2002.

[7] R. T. Faghih, K. S. Aaron and E. N. Brown, "Automated ovarian follicular monitoring: a novel real-time approach," 2017 39th Annual International Conference of the IEEE Engineering in Medicine and Biology Society (EMBC), Seogwipo, pp. 632-635, 2017.

[8] M. P. Aarti and B. S. Nidhi, "Comparative study on ovarian follicle detection using segmentation techniques," International Journal of Innovative Research in Computer and Communication Engineering, vol. 4, no. 9, pp. 16683-16689, September 2016.

[9] Y. Deng, Y. Wang and Y. Shen, “An automated diagnostic system of polycystic ovary syndrome based on object growing," Artificial Intelligence in Medicine, vol. 51, no. 3, pp. 199-209, November 2010.

[10] R. Sitheswaran and S. Malakhodi, "An effective automated system in follicle identification for polycystic ovary syndrome using ultrasound image," 2014 International Conference on Electronics and Communication Systems (ICECS), Coimbatore, pp. 1-5, 2014.

[11] N. H. Mahmood, N. Zulkarnain, N. S. A. Zulkifli, "Ultrasound Liver Image Enhancement Using Watershed Segmentation Method," International Journal of Engineering Research and Applications (IJERA), vol. 2, no. 3, pp. 691-694, 2012.

[12] M. J. Lawrence et al., "Computer assisted detection of polycy stic ovary morphology in ultrasound images, " Fourth Canadian Conference on Computer and Robot Vision (CRV '07), Montreal, Que., pp. 105-112, 2007.

[13] Adiwijaya et al., "Follicle detection on the USG images to support determination of polycystic ovary syndrome," Journal of Physics: Conference Series, vol. 622, pp. 255-262, 2015.

[14] P. S. Hiremath and J. R. Tegnoor, "Automatic detection of follicles in ultrasound images of ovaries using edge based method," in International Journal of Computer Applications, pp. 120 - 125, January 2010.

[15] S. S. Deshpande and A. Wakankar, "Automated detection of polycystic ovarian syndrome using follicle recognition," 2014 IEEE International Conference on Advanced Communications, Control and Computing Technologies, Ramanathapuram, pp. 1341-1346, 2014.

[16] B. Purnama, U. N. Wisesty, Adiwijaya, F. Nhita, A. Gay atri and T. Mutiah, "A classification of poly cy stic ovary syndrome based on follicle detection of ultrasound image," 2015 3rd International Conference on Information and Communication Technology (ICoICT), Nusa Dua, pp. 396-401, 2015.

[17] B. Padmapriy a and T. Kesavamurthy, "Detection of follicles in polycystic ovarian syndromne in ultrasound images using morphological operations," Journal of Medical Imaging Health Informatics, vol. 6, no. 1, pp. 240, February 2016

[18] P. S. Hiremath and J. R. Tegnoor, "Automatic detection of follicles in ultrasound images of ovaries using active contours method," 2010 IEEE International Conference on Computational Intelligence and Computing Research, pp. 286-291, 2010.

[19] P. S. Hiremath and J. R. Tegnoor, "Fuzzy inference system for follicle detection in ultrasound images of ovaries," in Soft Computing, vol. 18, no. 7, pp. 1353-1362, July 2014.

[20] H. P. Kumar and S. Srinivasan, "Fast automatic segmentation of polycystic ovary in ultrasound images using improved Chan-Vase with Split-Bregman optimization," Journal of Medical Imaging and Health Informatics, vol. 5, no. 1, pp. 57-62, February 2015.

[21] D. P. Lestari et al,. "Comparison of Three Segmentation Methods for Breast Ultrasound Images Based on Level Set and Morphological Operations," International Journal of Electrical and Computer Engineering (IJECE), vol.7, no. 1, pp.383-391, February 2017.

[22] D. L. Pham, C. Xu and J. L Prince, "Current Methods in Medical Image Segmentation," Annual Reviews of Biomedical Engineering, vol. 2, pp.315-337, August 2000.

[23] P. Mehrotra et al., "Automated ovarian follicle recognition for polycystic ovary syndrome," 2011 International Conference on Image Information Processing, Shimla, pp. 1-4, 2011.

[24] S. Rihana, H. Mousallem, C. Skaf and C. Yaacoub, "Automated algorithm for ovarian cysts detection in ultrasonogram," 2013 2nd International Conference on Advances in Biomedical Engineering, Tripoli, 2013, pp. 219-222, 2013.

[25] A. Raj, "Detection of cysts in ultrasonic images of ovary," International Journal of Science and Research (IJSR), vol. 2, no. 8, pp. 185-189, August 2013.

[26] J. Park et al., "Automatic Segmentation of Brachial Artery based on Fuzzy C-Means Pixel Clustering from Ultrasound Images," International Journal of Electrical and Computer Engineering (IJECE), vol. 8, no. 2, pp. 638-643, April 2017.

[27] V. Kiruthika and M.M. Ramya, “Automatic segmentation of ovarian follicle using K-means clustering, " 2014 Fifth International Conference on Signal and Image Processing, Bangalore, India, pp. 137-141, 2014.

[28] H. Lee, D. H, Song and K. B. Kim, "Effective Computers-Assisted Automatic Cervical Vertebrae Extraction with Rehabilitative Ultrasound Imaging by using K-Means Clustering," International Journal of Electrical and Computer Engineering (IJECE), vol. 6, no.6, pp. 2810-2817, December 2016. 